\title{
Surgical management of intrathoracic goitres
}

\author{
Ricard Simó ${ }^{1}$ lain J. Nixon ${ }^{2}$ - Vincent Vander Poorten ${ }^{3} \cdot$ Miquel Quer $^{4} \cdot$ Ashok R. Shaha $^{5} \cdot$ Alvaro Sanabria $^{6}$. \\ Fernando Lopez Alvarez ${ }^{7} \cdot$ Peter Angelos $^{8}$. Alessandra Rinaldo ${ }^{9}$. Alfio Ferlito ${ }^{9}$
}

Received: 10 June 2018 / Accepted: 16 November 2018 / Published online: 30 November 2018

(c) Springer-Verlag GmbH Germany, part of Springer Nature 2018

\begin{abstract}
Background Intrathoracic goitres (ITG) often present with compressive symptoms and require specialised care by experienced surgical teams. Most ITG can be accessed by a transcervical approach (TCA) and only between 1 and $15 \%$ will require an extracervical approach (ECA). Many controversies exist regarding the clinical presentation, evaluation, selection of cases for ECA, surgical technique and outcomes. This paper reviews the recent literature on the management, outcomes and evidence-based treatment strategies of ITG.

Methods We conducted a review of the literature on the evaluation, management and outcomes of surgery for ITGs.

Results The incidence of cancer in the ITGs ranges between 4 and 20\%. Multiplanar CT scanning offers the best preoperative evaluation and aids to determine the approach. Most ITG can be accessed by TCA and ECA are only needed in maximum $15 \%$ of cases. In experienced hands, the outcome of these surgeries is comparable to thyroid surgery for non-ITG.

Conclusions Surgery for ITG is challenging. The experienced surgeon however, with few exceptions can address ITG via TCA, with outcomes comparable to those of uncomplicated thyroid surgery.
\end{abstract}

Keywords Intrathoracic goitres $\cdot$ Retrosternal goitres $\cdot$ Substernal goitres $\cdot$ Thyroidectomy

\section{Introduction}

Multinodular goitre (MNG), defined as an enlarged thyroid gland with multiple nodules, affects $4 \%$ of the US population and $10 \%$ of the British population [1] and it is estimated to affect 1.5 billion people globally. Iodine-deficiency contributes to the vast majority of cases of MNG worldwide, resulting in a presumed over-secretion of thyroid stimulating hormone (TSH). This results in a benign proliferation of hyperplastic follicles, adenomatoid nodules, some with

Ricard Simó

ricard.simo@gstt.nhs.uk

1 Department of Otorhinolaryngology Head and Neck Surgery, Guy's and St Thomas' Hospital NHS Foundation Trust, St Thomas's Street, SE1 9RT London, UK

2 Department of Otorhinolaryngology Head and Neck Surgery, Edinburgh Royal Infirmary, Edinburgh, UK

3 Department of Otorhinolaryngology Head and Neck Surgery, Department of Oncology, Section Head and Neck Oncology, University Hospitals Leuven, Leuven, Belgium

4 Department of Otorhinolaryngology Head and Neck Surgery, Hospital de San Pau Universitat Autonoma de Barcelona, Barcelona, Spain cystic degeneration. MNG may present to the surgeon for diagnostic and therapeutic purposes. Classic indications for surgery in these patients include pressure effects and cosmesis, a recognised risk of malignancy, and intrathoracic extension [2].

Retrosternal, substernal and intrathoracic goitres are terms used to describe a subgroup of MNG that extend towards the thoracic cavity. These require specific preoperative evaluation and specialised surgical management, since a significantly higher risk of intra- and postoperative

5 Department of Head and Neck Surgery, Memorial Sloan-Kettering Cancer Center, Cornell University Medical College, New York, USA

6 Department of Surgery, Universidad de Antiloquia, Medellin, Colombia

7 Department of Otorhinolaryngology Head and Neck Surgery, Hospital Universitario de Asturias - Universidad de Asturias, Oviedo, Spain

8 Department of Surgery, University of Chicago Medical Centre, Chicago, USA

9 Otorhinolaryngology Head and Neck Surgery, University of Udine School of Medicine, Udine, Italy 
complications is observed when compared to mere cervical MNG [3]. The most common and appropriate term is Intrathoracic goitre (ITG) [4] and this term will be applied throughout this article.

The aim of this paper was to review the recent published literature on "the state of art" current management, predictors of approach, outcomes and evidence-based treatment strategies of ITG.

\section{Methods}

A medline search up to April 2018 was conducted using keywords that included "intrathoracic", "retrosternal", "substernal", "mediastinal", "goitre”, "goiter”, “multinodular" and "thyroidectomy". Articles were critically appraised specifically assessing preoperative evaluation, indications for surgery, surgical strategy, predictors of ECA and outcomes, complications and risk factors for complications. We excluded small series, case reports and technical notes. We also excluded papers relating to epidemiology and risk of cancer as it was felt not relevant to the paper.

\section{Definition of intrathoracic goitre}

Since the nineteenth century, ITG has been referred as retrosternal, substernal, retroclavicular and intrathoracic amongst others. The reason for this diversity is the lack of consensus on the proportion of the gland that is in an intrathoracic position, or how deep a cervical goitre must have descended to start classifying as ITG [5]. Numerous classifications have been proposed and compared, but none of them have been universally validated nor accepted [4, 6]. Huins et al. recommended a classification in to 3 grades depending on the relationship of the ITG with the aortic arch (AA) and the right cardiac auricle [6]. Recently Rios et al. al critically analysed all previous classifications of ITG for their capacity to predict intra- and post-operative complications, and found most definitions of ITG not clinically relevant. They concluded that Katlic's definition is the most useful for predicting a possible sternotomy for removing the goitre $[4,7]$.

\section{Current indications for surgery}

Surgery is the treatment of choice for symptomatic ITG (dyspnea, dysphagia or superior vena cava syndrome) [8], since (1) radioactive iodine ablation (RIA) implies a possible acute reaction causing airway obstruction, (2) most ITG tend to grow, (3) up to $25 \%$ of ITG contain malignant disease [2] and (4) up to $90 \%$ of ITG can be safely excised via a transcervical approach $[9,10]$. Some authors argue the need for surgical intervention in asymptomatic patients with incidentally diagnosed goitres during other investigations, especially in elderly individuals or significant co-morbid patients [11]. These may represent up to $40 \%$ of all ITG [11-14]. The only alternative when there are medical contraindications to surgery is RIA, the effect of which was recently estimated as a $40 \%$ volume reduction with accompanying symptom reduction [9].

In summary, any decision-making regarding surgery in this patient group should be individualised and based upon the size of the goitre, the degree of aero-digestive tract compression, the co-morbidities of the patient and the trajectory of growth in active surveillance.

\section{Preoperative evaluation}

Evaluation of a suspected ITG includes full history and examination including fibreoptic nasendoscopy (FNE), baseline thyroid function tests (TFT), thyroid autoantibody screen, ultrasound guided fine-needle aspiration cytology (USgFNAC) and CT or MRI scanning [15]. The use of flow volume loops may detect subradiological tracheal compression, but rarely influences management in patients with ITG [16].

Whereas USgFNAC is now considered the gold standard to evaluate thyroid nodules, it is not routinely applied to patients with ITGs because access is difficult and the risk of occult malignancy is thought to be low $[2,17]$. In reality, the risk of occult malignancy in ITGs is between 10 and 35\%, with younger patients, those with prior irradiation, a family history of thyroid malignancy or compression symptoms at a higher risk [2]. Therefore, also in ITG, an attempt at preoperative diagnosis is warranted, despite the potentially non-diagnostic samples may be non-diagnostic or very difficult to obtain [18].

\section{Predictors of surgical approach}

Multiplanar computerised tomography (MCT) is considered the best tool to aid to determine the most appropriate surgical approach $[6,19,20]$. MCT defines the extent, anatomical location and the relationship of the ITG to the trachea, oesophagus, great vessels, main bronchi, lungs and pericardium. It provides an objective measure of tracheal diameter to help preoperative anaesthetic planning. MCT also identifies nodal disease and other potential correlates of malignant disease such are irregular margins, heterogeneous internal features and the presence of microcalcification. Also the presence of gross capsular calcification is associated with difficult dissection from the surrounding anatomical structures and thus may help to select patients for extracervical approaches [12, 21, 22]. The Huins et al. criteria are based on MCT, and classify ITG as retroclavicular, above upper border of AA and below AA. They provide a reproducible 
classification, that constitute currently one of the best validated classifications as a predictor of surgical approach, and as such has been adopted by the British Association of Endocrine and Thyroid Surgeons [6]. Besides MCT, other elements to put in the balance in preoperative evaluation emerged. In 2005 Flati et al. introduced the term "iceberg" shape as a factor implying need for ECA [23]. In 2006, Sancho et al. reported 35 patients undergoing surgery for ITG, and found that a goitre weight of $260 \mathrm{~g}$ and extension to the tracheal carina were significant predictors of ECA. Their ECA rate of $37 \%$ was significantly higher than any other series in the literature [24]. Recently, Simo found that revision surgery for recurrent goitres, "iceberg" shaped glands and goitres extending beyond the AA most likely require ECA [17]. The indications for ECAs, could be categorised as high risk, moderate risk and low risk based on MCT and the experience of each surgical team [17] (Table 1). That said, the majority of ITG can be excised by experienced surgeons via a TCA [9]. Prospective data reveal the overall rate of ECA ranging from 0 to $1.7 \%$ [12].

\section{ITG with extension beyond the AA}

Extension of ITG beyond the AA has frequently been associated with an increased need of ECA. Grainger et al. found that MCT evidence of ITG reaching or extending to the AA increased the relative risk of sternotomy in multivariate analysis by 4.3 [20]. Riffat et al. in a cohort of 97 patients evaluated by preoperative MCT, found that there was a "relative" but statistically significant risk of sternotomy in ITG with

Table 1 Risk stratification for ECA in ITG. Patients with ITGs could be stratified according to the potential risk of needing an extra-cervical approach into 3 main categories depending on the clinical, surgical and anatomical features

High-risk patients for ECA

ITG below the AA

Recurrent goitres with intrathoracic extension to and below the

AA

Giant extension

Goitres involving multiple mediastinal compartments

Goitres with separate components

Goitres with "iceberg" or conical

shape

Goitres with extension to the posterior pleura

\section{Moderate-risk patients for ECA}

Low-risk for ECA

\footnotetext{
Goitres reaching the aortic arch Goitres reaching the aortic arch with oval or tubular shape Goitres with minimal posterior mediastinal, retrotracheal

Goitres with retroclavicular extension
}

posterior mediastinal extension, "conical" shape, ectopic goitre, and evidence of nodal disease [19].

\section{Revision and recurrent ITG with extension to the AA}

Revision cases are associated with an increased risk of haemorrhage and injury to vascular and visceral structures due fibrosis and distortion of anatomical and surgical planes $[12,25]$.

\section{ITG extending to the posterior mediastinum: retrotracheal and retroesophageal}

Extension to the posterior mediastinum makes the access via TCA difficult and hazardous. The angle of dissection is awkward and makes visualisation of the anatomy difficult. In these cases the recurrent laryngeal nerve (RLN) is likely to be in a more anterior position and therefore more vulnerable to injury [26]. If these goitres also reach the posterior pleura the risk of iatrogenic uncontrolled pneumothorax is real [17].

\section{ITG affecting both anterior and posterior mediastinum}

An ECA in these goitres also carries an increased risk. By definition these goitres ride over the brachiochephalic vascular bundle causing distortion of these vessels and possibly the RLN [26, 27]. It is therefore much safer to approach them from the anterior position via midline sternotomy rather than from a cranio-caudal angle where these structures are not in direct view.

\section{"Iceberg" or "conical" shape: intrathoracic component much larger than cervical component}

This shape of goitre implies a potential need for an ECA [19]. According to Simo three different shapes (oval, tubular and iceberg or cone) can be discerned, and relate to the approach needed (Fig. 1). The iceberg or cone shape carries a statistically significantly elevated risk of needing an ECA [17]. Thus, this shape evaluation should be part of the surgical planning for ITG [17].

\section{Giant extensions}

Sancho et al. reported a weight of over $250 \mathrm{~g}$ as a statistically significant predictor of an increased need for an ECA [24]; goitres of this weight generally much more difficult to deliver via the thoracic inlet [26]. 


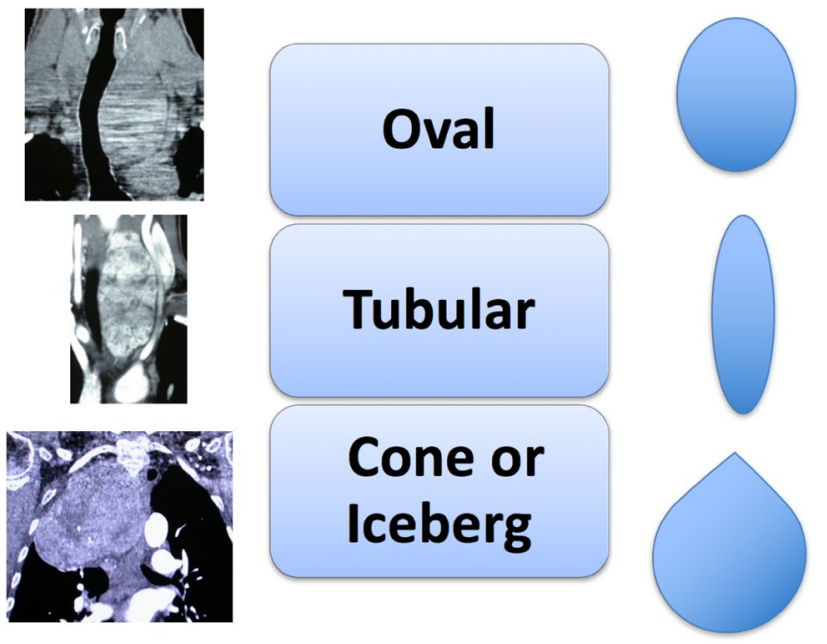

Fig. 1 Shape of the goitre into 3 main categories, oval, tubular and cone or "Iceberg"

\section{Multiple components: primary goitres-isolated intrathoracic goitres-minimal cervical component}

ITG can present with multiple components which are either not connected to each other, or only via a minimal fibrotic connecting remnant [27]. When such an ectopic element cannot be accessed via a TCA, it is usually also impossible to exert upward traction via the connecting string, complicating removal in a cranial direction, and implying the need for an ECA [9, 17].

\section{Anaesthesia, intubation and intraoperative care}

ITG can be associated with significant laryngotracheal compression and deviation resulting in challenging orotracheal intubation. Prior to surgery, the surgeon and anaesthetist must discuss the airway plan and review all imaging together. In most cases tracheal compression is soft in nature and can easily be overcome on gentle insertion of an adequately sized endotracheal tube. This usually is one size smaller than standard for such a patient. In order to avoid the dreaded emergency scenario of 'can't intubate, can't ventilate' at induction of anaesthesia in a paralysed patient, the anaesthetic team may choose to perform an awake fibreoptic oral or nasal tracheal intubation with the aid of topical local anaesthesia [8, 28].

The majority of patients with ITG are amenable to endotracheal intubation, as the tube splints the trachea open at the area of maximal compression. Airway management, however, may not always be straightforward. Many patients have variable symptoms related to head position. When the neck is fully extended, the goitre is pulled up towards the thoracic inlet, and the patient may find this position compromises the airway. In such cases, awake fibreoptic intubation is compatible with neck flexion during intubation. Truly difficult intubations in planned elective surgery are extremely uncommon [8].

In cases where extensive mediastinal dissection is anticipated, a double-lumen endotracheal tube may be required to permit selective pulmonary ventilation [8, 28].

Maintenance of anaesthesia implies no special requirements. At the end of surgery, tracheal compression resulting from longstanding goitres may cause a degree of tracheomalacia, however extubation is almost always possible. In the highly unlikely event that the patient suffers airway obstruction on extubation due to tracheomalacia, reintubation should be straightforward and an elective tracheostomy performed at a later stage if necessary [29].

\section{Surgical strategy}

Surgery for ITG poses significant intraoperative and postoperative challenges. It should best carried-out by experienced surgeons within a dedicated multidisciplinary thyroid team (endocrinologist, anaesthetist, endocrine head and neck and thoracic surgeons) in an appropriate setting. This will facilitates adequate planning and reduces unplanned ECA and unexpected complications [8, 17].

For patients with bilateral thyroid enlargement, total thyroidectomy is the procedure of choice. However, in patients where the ITG arise from one thyroid lobe, lobectomy is a perfectly accepted option [8]. Thyroid lobectomy can also be sufficient in selected high-risk patients, where a selective strategy may resolve the symptoms, while reducing the risk of complications such as bilateral RLN paralysis, tracheostomy and permanent hyperparathyroidism. This philosophy is shared by some authors [8] but not by others [30].

When considering less-than-total thyroidectomy, TFT and histopathology have to been taken into account. Euthyroid patients with unilateral goitres can be helped using a selective approach whereas hyperthyroid patients require a total thyroidectomy to eradicate symptoms of toxicity [8]. Following FNA, truly benign unilateral goitres can safely undergo a selective approach. FNA indicating "follicular neoplasm" should be considered for a total thyroidectomy and those with FNAC indicating malignancy require a total thyroidectomy [18].

When performing a lobectomy for ITG, dividing the isthmus at an early stage in the procedure facilitates the cervical dissection. This strategy can also be followed in large bilateral goitres, after which the procedure essentially becomes 2 lobectomies. In these cases starting the dissection with the smaller lobe will facilitate the dissection of the larger lobe [8, 9, 31]. 


\section{Outcomes of surgery for ITG}

Complications associated with thyroidectomy for ITGs may have been underestimated. ITG which extend to the carina tracheae are reported to carry a high risk of unplanned sternotomy, postoperative complications, return to the operating theatre for reoperation and even death [24]. Evidence-based data on ITG management, especially comparing surgical approaches is scarce, and the majority of evidence is level $\mathrm{V}$ [12].

\section{Injury to the RLN}

Voice changes are common after thyroid surgery. Between $30 \%$ and $87 \%$ of patients have subjective voice changes without demonstrable neural injury (endotracheal tube injury and oedema or laryngeal oedema secondary to venous stasis and fibrosis) [32]. On the other hand, RLN injury can result in vocal fold immobility, inducing voice changes, dysphagia (mainly for liquids) and even aspiration pneumonia. Bilateral RLNP can be associated with acute airway obstruction and the need for tracheostomy or other airway widening procedures which themselves cause a negative impact in voice and QOL [32]. The rate of RLN injury in ITG ranges from 0 to $14.3 \%$ with a mean rate of $2.7 \%$. Most series report a permanent rate between 2 and $4 \%$ and in view of the complexity of these cases, this appears to be an acceptable incidence $[33,34]$. There is however variability in reporting the rate of RLN injury, since some authors use "total procedure number" in the denominator, as opposed to others who userightfully- "nerves at risk" in that instance [9]. Evidently, the latter is to be preferred: hemithyroidectomies carry half the risk of total thyroidectomies. A recent Italian multicentre study, including 14,993 patients, compared the rate of RLNP in patients undergoing total thyroidectomy for cervical MNG and ITG via a transcervical versus using a manubriotomy. The authors found a statistically significant difference in the rate of transient RLNP $(0.5 \%$ in the cervicotomy group as opposed to $8 \%$ in the manubriotomy group) and of permanent RLNP $(0 \%)$ in the cervicotomy group as opposed to $4 \%$ in the manubriotomy group [35]. Factors associated with an increased risk of RLNP are gland volume, distortion of the anatomy (nerves riding over the intrathoracic component requiring longer segment dissections), the complexity of the surgery, and elderly patients with comorbidities with less resilient neural tissues $[35,36]$.

\section{Intraoperative neuromonitoring (IONM)}

The RLN may be difficult to identify and protect intraoperatively, especially in cases of invasive thyroid cancer, large goitres-ITG, and revision surgery. IONM has been reported to be useful aid for localising and monitoring the electrophysiological status of the RLN and EBSLN [37, 38]. Notwithstanding the purported benefits, several studies over the past 20 years have failed to demonstrate an statistically significant difference in the rates of permanent vocal fold paralysis when comparing use of IONM versus visual RLN identification alone in routine thyroid surgery [39-42], a result that was confirmed in a recent systematic review of 42 studies with over 64,000 nerves at risk [43]. Whilst the benefits of IONM for routine thyroid surgery are debated, IONM is widely accepted to be beneficial in the context of high-risk thyroidectomies. IONM has been shown to reduce the rate of RLN injury during revision surgery [44], or when neck anatomy is complex, e.g. in large goitres [45]. "Not using IONM" was an independent risk factor for permanent RLN injury in a recent paper of 2556 patients undergoing total thyroidectomy, both in univariate and multivariate analysis [17].

\section{Postoperative hypocalcaemia}

Surgery for ITG implies an increased risk of hypocalcaemia due to more difficult identification of the parathyroid glands [46, 47]. In a recent multicentric analysis by Testini et, the rate of transient hypocalcaemia in large goitre surgery was $33 \%$. In the same study the risk of permanent hypocalcaemia was $2.1 \%$ if a TCA was used and $2.9 \%$ if an ECA was needed. In patients who undergo reoperative or revision surgery, the risk of hypocalcaemia it is perceived to be higher however, it is difficult to find a figure of true incidence $[12,47]$. Specifically in ITG, the inferior parathyroid glands become more displaced and by definition they may become intrathoracic, whereas the superior parathyroid often maintains its original position and is more readily identifiable [48] .

\section{Tracheomalacia}

Problematic tracheomalacia in ITG is rare and its existence even controversial. Recent studies in Western countries have suggested that the prevalence of tracheomalacia in ITG is between 0 and $1.5 \%$ [49,50]. Lacoste et al. followed a cohort of 3008 patients undergoing thyroidectomy, none of whom developed tracheal collapse after surgery [51]. Benett et al. conducted a study with over 2000 patients with a heterogeneous definition of ITG, included goitres of different sizes rather than defined by "volume capable of airway compression" (goitre size greater than 100 g) [52]. Simo found that the rate of tracheomalacia in patients presenting with ITG is $1.6 \%$ [17]. Surgeons working in endemic goitre areas have reported higher rates (eg $3.1 \%$ and 5.8\%) [53, 54]. In India Agarwal et al. identified 28 of 900 thyroidectomy patients $(3.1 \%)$ who required treatment for tracheomalacia, with $26(2.8 \%)$ receiving a tracheostomy [55]. This group 
recently published additional work noting the persistence of the tracheomalacia phenomenon in patients with large goitre [53]. In another report from Sudan, 6 (5.8\%) of 103 patients undergoing thyroidectomy for a large goitre had tracheomalacia, with $5(4.8 \%)$ requiring a tracheostomy [56]. Heterogeneity of goitre sizes is a factor that could account for the variation in tracheomalacia prevalence.

It is unclear what the factors leading to tracheomalacia are, however it appears that preoperative acute airway obstruction heralds postoperative problematic tracheomalacia (two patients with tracheomalacia in the study of Simo presented preoperatively with acute airway obstruction due to a large bilateral ITG). Lacoste et al. suggested that the main causes of postoperative respiratory obstruction are wound hematoma, bilateral RLN palsies, and laryngeal oedema [49]. These findings were supported by several other reports. Therefore, a diagnosis of tracheomalacia requires exclusion of these diagnoses [50, 51, 56, 57]. Agarwal recently stated that the intraoperative diagnosis of tracheomalacia requires one or more of the following criteria: (1) soft and floppy trachea on palpation at the end of thyroidectomy; (2) obstruction to spontaneous respiration during gradual withdrawal of the endotracheal tube after thyroidectomy; (3) difficulty in advancing the suction catheter beyond the endotracheal tube after gradual withdrawal; and finally (4) that after closure of the wound, tracheomalacia can be suspected if there is absence of peri-tubal leak on deflation of the endotracheal tube cuff, absence of volume pressure loop on ventilator or development of respiratory stridor along with a falling haemoglobin oxygen saturation on pulse oximetry despite the administration of increasing $\mathrm{FiO} 2$ [55]. Large series of tracheomalacia patients have not revealed a clinically significant link between stridor and tracheomalacia as either a sensitive or specific diagnostic criteria. Agarwal found stridor in only a quarter of patients (7/28) [55].

\section{Mortality}

Mortality in ITG surgical series ranges from 0 to $15.3 \%$, and is higher in patients who have malignant disease or when surgery becomes urgent due to severe worsening respiratory symptoms [58]. Di Crescenzo et al. reported a mortality ranging from $2 \%$ in cervical approaches to $15.3 \%$ in patients requiring sternotomy [59]. Sancho et al. reported mortality of $5.7 \%$, increased in patients in which the goitre reached the carina [24]. The causes of death relate to severe postoperative complications such as sternotomy dehiscence and tracheobronchial fistula. Other authors reported a $0 \%$ incidence of death following surgery for ITG $[8,17]$. This can be attributed to careful patient selection, preoperative evaluation and optimisation, multidisciplinary team working and perfect postoperative care. Patients requiring sternotomy or lateral thoracotomy should be kept intubated and ventilated overnight in the Intensive Care Unit and this reduces the risk of severe postoperative complications such as fatal bleeding and cardiovascular events [48].

\section{Infection}

The risk of infection is low and represents around 1-2\% of patients undergoing thyroid surgery [60]. The risk of infection increases with the complexity of the procedure, whether neck dissection is done and when ECA is used [24]. The risk of wound infection is not discussed in most recent papers reporting outcomes of surgery for ITG. Sancho et al. reported a $6 \%$ incidence of pneumonia, a $3 \%$ of catheter related sepsis and $3 \%$ of postoperative urinary tract infection, but there is no indication of wound infection despite one patient suffering sternotomy dehiscence, which resulted in death [24].

\section{Haemorrhage}

Postoperative haemorrhage after thyroid surgery can be lifethreatening. It can lead to laryngeal oedema and potential airway obstruction including death. The majority of these bleedings occur in the first $8 \mathrm{~h}$ of surgery [61]. Godballe et al., collecting data from the National Danish Thyroid Data Base in 2009, produced the most complete account on postoperative bleeding after thyroid surgery. The rates of haemorrhage ranged from 1.9 to $14.3 \%$ with a mean rate of $4.2 \%$ [61]. Factors increasing the risk of postoperative haemorrhage included patient's age over 50 years, malignant histology, male gender, bilateral procedures and ITGs [8]. Simo found a $1.2 \%$ rate of postoperative haemorrhage in patients undergoing surgery for ITG. In all patients the onset of the bleeding was in the first $8 \mathrm{~h}$ after surgery and it was associated in all patients with coughing episodes [17].

\section{Pneumothorax and other complications}

The risk of pneumothorax in patients undergoing cervical approach is minimal. When it occurs, this is probably a result of blind finger dissection. The risk of pneumothorax in patients undergoing ETA is higher [17]. The majority of these injuries are intentional and a result of the surgical approach in order to adequately dissect the intrathoracic component adherent to the mediastinal pleura. The insertion of an intrathoracic intrapleural drains solves the problem [17]. Other complications to neighbouring anatomical organs, mainly in malignant disease, include injuries to trachea, oesophagus, phrenic nerve, and cardiac arrhythmias [62] but the reported rates rare. 


\section{Tracheostomy}

Published rates of need for a tracheostomy average between 2 to $3 \%$ and are related to bilateral RLN injury or tracheomalacia $[8,63]$. Randolph et al. reported a low threshold for temporary tracheostomy in cases where there was a concern for laryngeal oedema or in cases of known preoperative unilateral vocal cord dysfunction where contralateral vocal cord integrity was in question intraoperatively [8]. The rate of tracheostomy in Simo's series was 2.5\% [17]. A tracheostomy was more frequently needed in patients with severe tracheomalacia, bilateral RLN injuries, those undergoing total thyroidectomies, redo surgery and patients presenting with acute airway obstruction. These patients as well as those with previous preoperative RLN injury thus should have consented for elective tracheostomy.

\section{Minimally invasive approaches for the intrathoracic goitre}

Over the years, other approaches have been introduced to deal with ITG to minimise the risk of complications arising from midline sternotomies.

Lahey in 1920 was the first to recommend the incision of the ITG at its upper pole, breaking down its centre, sucking out its colloid contents allowing it to reduce its diameter so it could be extracted [64]. Allo and Thomson in 1983 suggested "gentle" insertion of a "soup spoon" into the mediastinum to facilitate removal of the gland [65].

Partial median sternotomy has been also described mainly in the management of cardiac conditions. In the management of ITGs, this approach has been described in reported series addressing outcomes but interestingly, we have not found a dedicated paper on this approach. Authors using this approach have reported good outcomes in selected cases. As it appears to reduce postoperative pain and length of stay, compared with full sternotomy [59, 66-68].

Har-El and Sundaram described the use the microdebrider for intracapsular reduction of ITG and facilitate its transcervical excision. They reported this technique in 11 patients with gigantic ITG as an alternative to midline sternotomy. They did not report any major complications, but concluded that this instrumentation should be utilised with caution [69].

The use of the mediastinoscope [70] and more recently the use of video-assisted mediastinoscope (VAM) have been introduced in the management of the ITG [71]. VAM allows the dissection of the mediastinal component of the goitre from the main thoracic structures up to the level of the carina, main bronchus, pulmonary arteries and superior vena cava under direct video-assisted view. On the left, it also allows the surgeon to identify the thoracic component of the recurrent laryngeal nerve. For patients with benign long standing ITG extending to the level or beyond the aortic arch, VAM is a feasible technique to avoid sternotomy. The VAM can be introduced through the same cervical incision to release the ITG from the major intrathoracic structures under direct vision and thus reducing the risk of injury to anatomical structures. However, despite careful videoguided dissection, there is a $0.4 \%$ reported risk of major bleeding, which may require a median sternotomy to control it [71]. The use of VAM can also help to control major haemorrhage.

Video-assisted thoracic surgery (VATS) has been recently introduced to aid the excision mediastinal and intrathoracic tumours avoiding the need for sternotomy. These include lung carcinomas, thymomas and intrathoracic parathyroid tumours. VATS has also been introduced to excise primary intrathoracic goitres and to aid the mobilisation of ITG [72].

The latest minimally invasive approach has been the introduction of robotic assisted thoracic surgery (RATS). This technique has all the advantages of 3D magnification, allowing better identification of the intrathoracic structures and hence making the excision of the goitre easier and with less complications [73] .

Although all these techniques have been reported to this day, they are mainly case reports, technical notes and short retrospective series. There is no doubt that they offer clear advantages and it is likely to play an important role in the future management of ITG.

\section{Summary}

Surgery for ITG is challenging. Patients must be appropriately evaluated with multiplanar CT scanning to determine the best surgical approach. Most ITG can be excised via a transcervical approach. The outcomes for ITG are potentially less favourable than for cervical goitre. However, in experienced hands and with careful planning and execution, surgery can be performed safely in the vast majority of patients.

\section{References}

1. Gittoes NJ, Miller MR, Daykin J, Sheppard MC, Franklyn JA (1996) Upper airways obstruction in 153 consecutive patients presenting with thyroid enlargement. Bmj 312(7029):484

2. Nixon IJ, Simo R (2013) The neoplastic goitre. Curr Opin Otolaryngol Head Neck Surg 21(2):143-149. https://doi.org/10.1097/ MOO.0b013e32835cec37

3. Rugiu MG, Piemonte M (2009) Surgical approach to retrosternal goitre: do we still need sternotomy? Acta otorhinolaryngologica Italica: organo ufficiale della Societa italiana di otorinolaringologia e chirurgia cervico-facciale 29 (6):331-338

4. Rios A, Rodriguez JM, Balsalobre MD, Tebar FJ, Parrilla P (2010) The value of various definitions of intrathoracic goiter for 
predicting intra-operative and postoperative complications. Surgery 147(2):233-238. https://doi.org/10.1016/j.surg.2009.06.018

5. Randolph G (2013) Surgery of thyroid and parathyroids

6. Huins CT, Georgalas C, Mehrzad H, Tolley NS (2008) A new classification system for retrosternal goitre based on a systematic review of its complications and management. Int J Surg 6(1):7176. https://doi.org/10.1016/j.ijsu.2007.02.003

7. Katlic MR, Grillo HC, Wang CA (1985) Substernal goiter. Analysis of 80 patients from Massachusetts General Hospital. Am J Surg 149(2):283-287

8. Randolph GW, Shin JJ, Grillo HC, Mathisen D, Katlic MR, Kamani D, Zurakowski D (2011) The surgical management of goiter: Part II. Surgical treatment and results. Laryngoscope 121(1):6876. https://doi.org/10.1002/lary.21091

9. Rios A, Sitges-Serra A (2012) [Surgical treatment of intrathoracic goitre]. Cirugia Espanola 90(7):421-428. https://doi. org/10.1016/j.ciresp.2012.01.003

10. Shaha AR, Alfonso AE, Jaffe BM (1989) Operative treatment of substernal goiters. Head neck 11(4):325-330

11. Landerholm K, Jarhult J (2015) Should asymptomatic retrosternal goitre be left untreated? A prospective single-centre study. Scandinavian J Surgery: SJS 104(2):92-95. https://doi. org/10.1177/1457496914523411

12. White ML, Doherty GM, Gauger PG (2008) Evidence-based surgical management of substernal goiter. World journal of surgery 32(7):1285-1300. https://doi.org/10.1007/s00268-008-9466-3

13. Cohen JP (2009) Substernal goiters and sternotomy. Laryngoscope 119(4):683-688. https://doi.org/10.1002/lary.20102

14. Chen AY, Bernet VJ, Carty SE, Davies TF, Ganly I, Inabnet WB 3rd, Shaha AR, Surgical Affairs Committee of the American Thyroid A (2014) American Thyroid Association statement on optimal surgical management of goiter. Thyroid 24(2):181-189. https://doi.org/10.1089/thy.2013.0291

15. Mehanna H (2008) Diagnosis and management of thyroid nodules. J ENT Masterclass 1(1):98-102

16. Stevens JL, Constantinides V, Todd J, Meeran K, Christakis I, Tolley NS, Palazzo FF (2014) Do flow volume loops alter surgical management in patients with a goitre? Clin Endocrinol 81(6):916920. https://doi.org/10.1111/cen.12539

17. Simo i Sanchez R (2017) Intrathoracic Goitres: Comparative study of the transcervical approach versus the combined cervicothoracic approach. PhD Thesis, Universitat Autonoma de Barcelona, Barcelona

18. Rios A, Rodriguez JM, Canteras M, Galindo PJ, Balsalobre MD, Parrilla P (2004) Risk factors for malignancy in multinodular goitres. Eur J Surg Oncol 30(1):58-62

19. Riffat F, Del Pero MM, Fish B, Jani P (2013) Radiologically predicting when a sternotomy may be required in the management of retrosternal goiters. Ann Otol Rhinol Laryngol 122(1):15-19

20. Grainger J, Saravanappa N, D'Souza A, Wilcock D, Wilson PS (2005) The surgical approach to retrosternal goiters: the role of computerized tomography. Otolaryngol Head Neck Surg 132(6):849-851. https://doi.org/10.1016/j.otohns.2005.01.039

21. Bin Saeedan M, Aljohani IM, Khushaim AO, Bukhari SQ, Elnaas ST (2016) Thyroid computed tomography imaging: pictorial review of variable pathologies. Insights into imaging 7(4):601617. https://doi.org/10.1007/s13244-016-0506-5

22. Qureishi A, Garas G, Tolley N, Palazzo F, Athanasiou T, Zacharakis E (2013) Can pre-operative computed tomography predict the need for a thoracic approach for removal of retrosternal goitre? International journal of surgery 11(3):203-208. https://doi. org/10.1016/j.ijsu.2013.01.006

23. Flati G, De Giacomo T, Porowska B, Flati D, Gaj F, Talarico C, Antonellis F, Diana M, Berloco PB (2005) Surgical management of substernal goitres. When is sternotomy inevitable? La Clinica terapeutica 156(5):191-195
24. Sancho JJ, Kraimps JL, Sanchez-Blanco JM, Larrad A, Rodriguez JM, Gil P, Gibelin H, Pereira JA, Sitges-Serra A (2006) Increased mortality and morbidity associated with thyroidectomy for intrathoracic goiters reaching the carina tracheae. Arch Surg 141(1):82-85. https://doi.org/10.1001/archsurg.141.1.82

25. Watkinson JC (2010) Fifteen years' experience in thyroid surgery. Ann R Coll Surg Engl 92(7):541-547. https://doi. org/10.1308/003588410X12699663905230

26. Vaiman M, Bekerman I (2017) Anatomical approach to surgery for intrathoracic goiter. Eur Arch Oto-Rhino-Laryngol 274 (2):1029-1034. https://doi.org/10.1007/s00405-016-4322-9

27. Foroulis CN, Rammos KS, Sileli MN, Papakonstantinou C (2009) Primary intrathoracic goiter: a rare and potentially serious entity. Thyroid 19(3):213-218. https://doi.org/10.1089/ thy.2008.0222

28. Dempsey GA, Snell JA, Coathup R, Jones TM (2013) Anaesthesia for massive retrosternal thyroidectomy in a tertiary referral centre. Br J Anaes 111(4):594-599. https://doi.org/10.1093/bja/aet151

29. Findlay JM, Sadler GP, Bridge H, Mihai R (2011) Post-thyroidectomy tracheomalacia: minimal risk despite significant tracheal compression. Br J Anaes 106(6):903-906. https://doi.org/10.1093/ $\mathrm{bja} / \mathrm{aer} 062$

30. Nakaya M, Ito A, Mori A, Oka M, Omura S, Kida W, Inayoshi Y, Inoue A, Fuchigami T (2016) Surgical treatment of substernal goiter: An analysis of 44 cases. Auris, nasus, larynx. https://doi. org/10.1016/j.anl.2016.02.016

31. Randolph G (2013) Surgery of the thyroid and parathyroid glands, vol 2. Elsevier, Philadelphia

32. Chandrasekhar SS, Randolph GW, Seidman MD, Rosenfeld RM, Angelos P, Barkmeier-Kraemer J, Benninger MS, Blumin JH, Dennis G, Hanks J, Haymart MR, Kloos RT, Seals B, Schreibstein JM, Thomas MA, Waddington C, Warren B, Robertson PJ (2013) Clinical practice guideline: improving voice outcomes after thyroid surgery. Otolaryngol Head Neck Surgery 148(6 Suppl):S1S37. https://doi.org/10.1177/0194599813487301

33. Jeannon JP, Orabi AA, Bruch GA, Abdalsalam HA, Simo R (2009) Diagnosis of recurrent laryngeal nerve palsy after thyroidectomy: a systematic review. Int J Clin Pract 63(4):624-629. https://doi.org/10.1111/j.1742-1241.2008.01875.x

34. Rios A, Rodriguez JM, Galindo PJ, Torres J, Canteras M, Balsalobre MD, Parrilla P (2008) Results of surgical treatment in multinodular goiter with an intrathoracic component. Surg Today 38(6):487-494. https://doi.org/10.1007/s00595-006-3673-z

35. Testini M, Gurrado A, Bellantone R, Brazzarola P, Cortese R, De Toma G, Fabiola Franco I, Lissidini G, Pio Lombardi C, Minerva F, Di Meo G, Pasculli A, Piccinni G, Rosato L (2014) Recurrent laryngeal nerve palsy and substernal goiter. An Italian multicenter study. J Visceral Surg 151(3):183-189. https://doi.org/10.1016/j. jviscsurg.2014.04.006

36. Randolph GW, Kobler JB, Wilkins J (2004) Recurrent laryngeal nerve identification and assessment during thyroid surgery: laryngeal palpation. World J Surg 28(8):755-760. https://doi. org/10.1007/s00268-004-7348-x

37. Cernea CR, Brandao LG, Brandao J (2012) Neuromonitoring in thyroid surgery. Current opinion in otolaryngology \& head and neck surgery 20 (2):125-129. https://doi.org/10.1097/MOO.0b013 e32834fa8e6

38. Barczynski M, Konturek A, Pragacz K, Papier A, Stopa M, Nowak W (2014) Intraoperative nerve monitoring can reduce prevalence of recurrent laryngeal nerve injury in thyroid reoperations: results of a retrospective cohort study. World J Surg 38(3):599-606. https ://doi.org/10.1007/s00268-013-2260-x

39. Shindo M, Chheda NN (2007) Incidence of vocal cord paralysis with and without recurrent laryngeal nerve monitoring during thyroidectomy. Arch Otolaryngol Head Neck Surgery 133(5):481485. https://doi.org/10.1001/archotol.133.5.481 
40. Dralle H, Sekulla C, Haerting J, Timmermann W, Neumann HJ, Kruse E, Grond S, Muhlig HP, Richter C, Voss J, Thomusch O, Lippert H, Gastinger I, Brauckhoff M, Gimm O (2004) Risk factors of paralysis and functional outcome after recurrent laryngeal nerve monitoring in thyroid surgery. Surgery 136(6):1310-1322. https://doi.org/10.1016/j.surg.2004.07.018

41. Barczynski M, Konturek A, Cichon S (2009) Randomized clinical trial of visualization versus neuromonitoring of recurrent laryngeal nerves during thyroidectomy. Br J Surg 96(3):240246. https://doi.org/10.1002/bjs.6417

42. Dralle H, Sekulla C, Lorenz K, Brauckhoff M, Machens A, German ISG (2008) Intraoperative monitoring of the recurrent laryngeal nerve in thyroid surgery. World J Surg 32(7):13581366. https://doi.org/10.1007/s00268-008-9483-2

43. Higgins TS, Gupta R, Ketcham AS, Sataloff RT, Wadsworth JT, Sinacori JT (2011) Recurrent laryngeal nerve monitoring versus identification alone on post-thyroidectomy true vocal fold palsy: a meta-analysis. Laryngoscope 121(5):1009-1017. https://doi. org/10.1002/lary.21578

44. Chan WF, Lang BH, Lo CY (2006) The role of intraoperative neuromonitoring of recurrent laryngeal nerve during thyroidectomy: a comparative study on 1000 nerves at risk. Surgery 140(6):866-872. https://doi.org/10.1016/j.surg.2006.07.017 (discussion 872-863)

45. Chiang FY, Lu IC, Chen HC, Chen HY, Tsai CJ, Lee KW, Hsiao PJ, Wu CW (2010) Intraoperative neuromonitoring for early localization and identification of recurrent laryngeal nerve during thyroid surgery. Kaohsiung J Med Sci 26(12):633-639. https ://doi.org/10.1016/S1607-551X(10)70097-8

46. Edafe O, Antakia R, Laskar N, Uttley L, Balasubramanian SP (2014) Systematic review and meta-analysis of predictors of post-thyroidectomy hypocalcaemia. Br J Surg 101(4):307-320. https://doi.org/10.1002/bjs.9384

47. Testini M, Gurrado A, Avenia N, Bellantone R, Biondi A, Brazzarola P, Calzolari F, Cavallaro G, De Toma G, Guida P, Lissidini G, Loizzi M, Lombardi CP, Piccinni G, Portincasa P, Rosato L, Sartori N, Zugni C, Basile F (2011) Does mediastinal extension of the goiter increase morbidity of total thyroidectomy? A multicenter study of 19,662 patients. Ann Surg Oncol 18(8):2251-2259. https://doi.org/10.1245/s10434-011-1596-4

48. Simo RNI, Ofo E (2015) Surgery for Intrathoracic Goitre (Retrosternal) goitres. Open access atlas of otolaryngology, head and neck operative surgery. University of Cape Town, Cape Town Southafrica

49. Randolph GW, Shin JJ, Grillo HC, Mathisen D, Katlic MR, Kamani D, Zurakowski D (2011) The surgical management of goiter: Part II. Surgical treatment and results. Laryngoscope 121(1):68-76

50. Findlay J, Sadler G, Bridge H, Mihai R (2011) Post-thyroidectomy tracheomalacia: minimal risk despite significant tracheal compression. Br J Anaes 106(6):903-906

51. Lacoste L, Montaz N, Bernit A-F, Gineste D, Lehuede M-S, Barbier J, Karayan J, Girault M, Fusciardi J (1993) Airway complications in thyroid surgery. Ann Otol, Rhinol Laryngol 102(6):441-446

52. Bennett A, Hashmi S, Premachandra D, Wright M (2004) The myth of tracheomalacia and difficult intubation in cases of retrosternal goitre. J Laryngol Otol 118(10):778-780

53. Agarwal A, Agarwal S, Tewari P, Gupta S, Chand G, Mishra A, Agarwal G, Verma A, Mishra S (2012) Clinicopathological profile, airway management, and outcome in huge multinodular goiters: an institutional experience from an endemic goiter region. World J Surg 36(4):755-760

54. Jokinen K, Palva T, Sutinen S, Nuutinen J (1977) Acquired tracheobronchomalacia. Ann Clin Res 9(2):52-57
55. Agarwal A, Mishra AK, Gupta SK, Arshad F, Agarwal A, Tripathi M, Singh P (2007) High incidence of tracheomalacia in longstanding goiters: experience from an endemic goiter region. World J Surg 31(4):832-837

56. Ahmed ME, Ahmed EO, Mahadi SI (2006) Retrosternal goiter: the need for median sternotomy. World J Surg 30(11): 1945-1948

57. Johnson TH, Mikita JJ, Wilson RJ, Feist J (1973) Acquired Tracheomalacia 1. Radiology 109(3):577-580

58. Gomez-Ramirez J, Sitges-Serra A, Moreno-Llorente P, Zambudio AR, Ortega-Serrano J, Rodriguez MT, del Moral JV (2015) Mortality after thyroid surgery, insignificant or still an issue? Langenbeck's archives of surgery /. Deutsche Gesellschaft fur Chirurgie 400(4):517-522. https://doi.org/10.1007/s0042 3-015-1303-1

59. Di Crescenzo V, Vitale M, Valvano L, Napolitano F, Vatrella A, Zeppa P, De Rosa G, Amato B, Laperuta P (2016) Surgical management of cervico-mediastinal goiters: our experience and review of the literature. Int J Surg 28(Suppl 1):S47-S53. https ://doi.org/10.1016/j.ijsu.2015.12.048

60. Dionigi G, Rovera F, Boni L, Castano P, Dionigi R (2006) Surgical site infections after thyroidectomy. Surg Infect 7(Suppl 2):S117-S120. https://doi.org/10.1089/sur.2006.7.s2-117

61. Godballe C, Madsen AR, Pedersen HB, Sorensen CH, Pedersen U, Frisch T, Helweg-Larsen J, Barfoed L, Illum P, Monsted JE, Becker B, Nielsen T (2009) Post-thyroidectomy hemorrhage: a national study of patients treated at the Danish departments of ENT Head and Neck Surgery. Eur Arch Oto-RhinoLaryngol 266 (12):1945-1952. https://doi.org/10.1007/s0040 5-009-0949-0

62. Sancho JJ, Prieto R, Duenas JP, Ribera C, Ripolles J, Larrad A, Sitges-Serra A (2012) A randomized trial of hemithyroidectomy versus Dunhill for the surgical management of asymmetrical multinodular goiter. Ann Surg 256(5):846-851. https://doi. org/10.1097/SLA.0b013e318272df62 (discussion 851-842)

63. Agarwal A, Mishra AK, Gupta SK, Arshad F, Agarwal A, Tripathi M, Singh PK (2007) High incidence of tracheomalacia in longstanding goiters: experience from an endemic goiter region. World J Surg 31(4):832-837. https://doi.org/10.1007/ s00268-006-0565-8

64. Lahey FH (1920) Diagnosis and management of intrathoracic goiters. JAMA Otolaryngol Head Neck Surgery 75:163-166

65. Allo MD, Thompson NW (1983) Rationale for the operative management of substernal goiters. Surgery 94(6):969-977

66. Maruotti RA, Zannini P, Viani MP, Voci C, Pezzuoli G (1991) Surgical treatment of substernal goiters. Int Surg 76(1):12-17

67. Vlastarakos PV, Trinidade A, Jaberoo MC, Mochloulis G (2016) A limited thoracocervical approach for accessing the anterior mediastinum in retrosternal goiters: Surgical technique and implications for the management of head and neck emergencies. Ear, nose, \& throat journal 95 (3):E39-43

68. Alifano M, Parri SN, Arab WA, Bonfanti B, Lacava N, Porrello C, Boaron M (2008) Limited upper sternotomy in general thoracic surgery. Surgery Today 38(4):300-304. https://doi. org/10.1007/s00595-007-3626-1

69. Har-El G, Sundaram K (2001) Powered instrumentation for transcervical removal of gigantic intrathoracic thyroid. Head neck 23(4):322-325

70. Tsai VW, Cameron RB, Wang MB (2006) Thyroidectomy for substernal goiter via a mediastinoscopic approach. Ear Nose Throat J 85(8):528-529

71. Migliore M, Costanzo M, Cannizzaro MA (2010) Cervicomediastinal goiter: is telescopic exploration of the mediastinum (video mediastinoscopy) useful? Interact Cardiovasc Thoracic 
Surg 10(3):439-440. https://doi.org/10.1510/icvts.2009.21763

72. Gupta P, Lau KK, Rizvi I, Rathinam S, Waller DA (2014) Video assisted thoracoscopic thyroidectomy for retrosternal goitre. Ann R Coll Surg Engl 96(8):606-608. https://doi. org/10.1308/003588414X14055925058634
73. Podgaetz E, Gharagozloo F, Najam F, Sadeghi N, Margolis M, Tempesta BJ (2009) A novel robot-assisted technique for excision of a posterior mediastinal thyroid goiter: a combined cervicomediastinal approach. Innovations 4(4):225-228. https://doi. org/10.1097/IMI.0b013e3181a69bf0 